\title{
Optimal Municipal Solid Waste Management of A City in North India
}

\author{
Neeraj Parashar, Sandeep Singla, Anuj Sachar, Anjali Gupta
}

\begin{abstract}
This paper studies the present system of collection, transportation and disposal of Municipal Solid Waste (MSW) being followed in the city of Panchkula, in North India. It is found that the present system of MSW management in Panchkula is unscientific, inefficient and a major potential environment and health hazard. The trends of waste generation and its qualitative as well as quantitative characteristics have been studied in this paper and paired comparison techniques tool has been used to arrive at the most suitable, sustainable and environment friendly solution for the management of $M S W$ in Panchkula. Each element of the proposed MSW management system has been discussed in detail. The paper leads to the conclusion that a participative, inclusive and decentralized system would be best suited for the city.
\end{abstract}

Keywords: Municipal solid waste, composting, ranking, land filling, segregation.

\section{INTRODUCTION}

The city of Panchkula with a population of approximately 2.37 lakhs (interpolated) is a well-planned and modern city of Northern India, located in the foothills of the Shivalik Range [1], [2], [3]. The system of Municipal Solid Waste Management (MSWM) in the city however leaves much to be desired and on the whole, is far from satisfactory and is having various adverse impacts. This single vital factor, if not adequately addressed soon, is likely to seriously affect the quality of life of its citizens in very near future. The following are some of the glaring shortcomings observed during the course of this study:-

$>$ Unprofessional and unscientific approach.

$>$ Inefficient and labor intensive method of municipal solid waste collection.

$>$ No segregation at source. Inefficient recycling of economically useful material.

$>$ Absence of engineered landfill or any treatment /processing/ waste to energy facility.

$>$ Open dumping in low lying area near residential sectors in complete violation of environmental regulations, leading to unhygienic conditions.

$>$ Inadequate awareness and involvement of the general public.

Revised Manuscript Received on July 22, 2019.

Neeraj Parashar, Sandeep Singla, Anuj Sachar, Department of Civil Engineering, RIMT University, Punjab, India.

Anjali Gupta, Department of Civil Engineering, Manav Rachna Institute of Research and Studies, Faridabad, India.
Litigation and opposition to shifting of dumping site closer to urban areas.

$>$ Non-Finalization of alternate site for landfill till date [4]. $>$ Quantity of bio-degradable waste being composted is insufficient and inefficient.

There is thus an urgent need to critically examine the existing system and to propose a suitable integrated approach/strategy for sustainable MSWM for the city.

\section{METHODOLOGY}

The study was carried out by actual physical inspection and verification of the various elements of the existing system. Detailed interaction with the individuals involved in the collection and disposal of the MSW was done and all observations were noted down. The open dump site at Sector-23 was visited multiple times and various aspects were examined in detail. In order to understand the perception, concerns, needs and priorities of the citizens of Panchkula as regards MSW management and related issues, a public survey was conducted by circulating a questionnaire and by informally interacting with residents. The information gathered from the response was taken into account in planning and developing the proposed suitable MSWM system. Further, the complete city as a whole was taken into consideration for the general and major aspects of the study, whereas a particular area (a residential Sector) was chosen for a detailed study as it was found to be a true representation of the urban set up in Panchkula. As all the sectors are almost identical, the results and conclusions of analysis of data are equally applicable to almost all other sectors. There are a total of 950 houses in the sector of which approximately 50 remain unoccupied at any time. The sector has 100 shops and showrooms of all types, 5 restaurants, 3 schools, 3 clinics and a large nursing home, some government offices, 2 workshops, various fruit and juice sellers and vegetable vendors, 6 small parks and a post office. The sector therefore was found to be an ideal representative sample location for the study. The data of solid waste collected from Sector 8 is presented in table 1 .

a) Periodicity and Method of Data Collection: The data in respect of waste generated by 130 houses was recorded at least twice every week over a period of six months (47 sets of observations taken). The population of these 130 houses was recorded to be 487 persons (children below 5 years were excluded). The overall data for the complete sector was taken intermittently, minimum once a week, over a period of three months (16 sets of observations). The data in respect of the 130 houses was recorded by unloading the cart used for collection and sorting the constituents and weighing

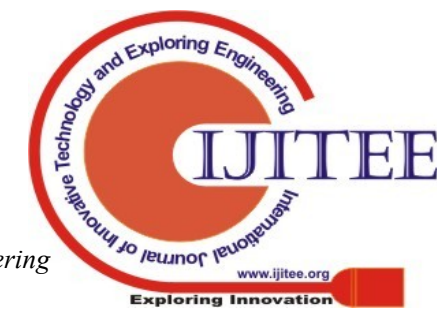




\section{Optimal Municipal Solid Waste Management of A City in North India}

them separately. Constituents like clothes/ textiles, wood, rubber, leather etc. were in very small quantities and thus it was impractical to measure the individual quantity. These have therefore been included in miscellaneous items. The constituents were roughly separated out and weighed. However, the results are approximate as it was extremely difficult to segregate the individual items, which only reinforces the fact that it is very important to segregate the MSW at generation source itself. Moreover, the data of the overall sector measured from the bins does not give a true picture as almost all the recyclables have been removed by the rickshaw / cart pullers and rag pickers. For the purposes of this study, the residents were requested not to sell any waste to the recyclers except newspapers (as it is easy to estimate their weight @12 newspapers $/ \mathrm{kg}$ ) and to dispose it in the MSW stream only. A few residents may still not have heeded to the request. The data of 130 houses is therefore a fairly accurate representation of the actual waste generated and its constituents.

b) Inert Matter: Apart from the above, the fine earth, pebbles, ash, leaves, branches etc. collected as a result of street sweepings were accurately measured by measuring the quantity deposited in the bins by each sweeper. These were not separated into individual constituents. These included a large quantity of street litter left by residents. The quantity was found to be $300 \mathrm{kgs}$ for the whole sector. In order to calculate per capita waste generation, proportionate quantity was taken as corresponding to 130 houses.

c) Recyclers: In addition, the recyclers or Kabariwallahs were also targeted. A total of 18-24 of them visit the sector every day and take away approximately 90-100 $\mathrm{Kg}$ of newspaper and card board and approximately 100-120 Kg of other types of waste like plastics, cans, bottles etc.

d) $C \& D$ Waste: The $C \& \mathrm{D}$ waste could not be ascertained as it is disposed at various locations in the city by residents through privately hired labour and transport and depends upon number of buildings under construction / repair.

Table 1: MSW Data of Sector 8 Panchkula Recorded

\begin{tabular}{|c|c|c|c|c|c|}
\hline $\begin{array}{l}\text { Sr. } \\
\text { No. }\end{array}$ & Item & $\begin{array}{l}\text { MSW } \\
\text { From 130 } \\
\text { Houses } \\
\text { Kg/Day }\end{array}$ & $\begin{array}{l}\% \\
\text { Constituents }\end{array}$ & $\begin{array}{l}\text { Total } \\
\text { for } \\
\text { Sector } \\
\text { Kg/Day }\end{array}$ & Remarks \\
\hline 1. & $\begin{array}{l}\text { Paper and } \\
\text { Cardboar } \\
\text { d }\end{array}$ & 5.0 & 2.8 & $10-15^{*}$ & $\begin{array}{l}* \text { Taken } \\
\text { away by } \\
\text { recyclers/r } \\
\text { ag pickers. }\end{array}$ \\
\hline 2. & $\begin{array}{l}\text { Plastic ( } \\
\text { Including } \\
\text { Milk } \\
\text { Packets) }\end{array}$ & 1.83 & 1.03 & $4-5^{*}$ & -do- \\
\hline 3. & Metal & 4.81 & 2.7 & $6-8^{*}$ & -do- \\
\hline 4. & $\begin{array}{l}\text { Glass/ } \\
\text { Ceramic }\end{array}$ & 0.67 & 0.3 & $4-5^{*}$ & -do- \\
\hline 5. & $\begin{array}{l}\text { Food and } \\
\text { Garden } \\
\text { Waste }\end{array}$ & 109 & 61.5 & $650-750$ & $\begin{array}{l}\text { Qty } \\
\text { increases } \\
\text { around } \\
\text { "Mandi" } \\
\text { days }\end{array}$ \\
\hline 6. & $\begin{array}{l}\text { Ash, Fine } \\
\text { Earth, } \\
\text { pebbles, } \\
\text { etc. }\end{array}$ & 43 & 24.3 & 300 & $\begin{array}{l}\text { Includes } \\
\text { street } \\
\text { litter. }\end{array}$ \\
\hline 7. & $\begin{array}{l}\text { Misc. } \\
\text { Items } \\
\text { (Includin } \\
\mathrm{g} \\
\text { newspape }\end{array}$ & 12.94 & 7.3 & $20-25 \$$ & $\begin{array}{l}\$ \\
\text { Newspape } \\
\text { rs sold to } \\
\text { recyclers. }\end{array}$ \\
\hline
\end{tabular}

\begin{tabular}{|l|l|l|l|l|l|}
\hline & r) & & & & \\
\hline & $\begin{array}{l}\text { Total } \\
\text { Kgs. }\end{array}$ & 177.25 & & & \\
\hline
\end{tabular}

Percentage Constituents and Per Capita Generation: The percentage of each of the constituent is given in the table 1 above. It is found that the per capita per day generation rate of MSW is $0.364 \mathrm{Kilograms}$ per person per day $(\mathrm{Kg} / \mathrm{p} / \mathrm{d})$ and it is found comparable to national average and the data of Chandigarh city $(0.40 \mathrm{Kg} / \mathrm{p} / \mathrm{d})$ analyzed by the Central Pollution Control Board, Ministry of Environment and forests and Climate Change [5].The constituent percentage is also depicted as pie chart in figure 1 below:-

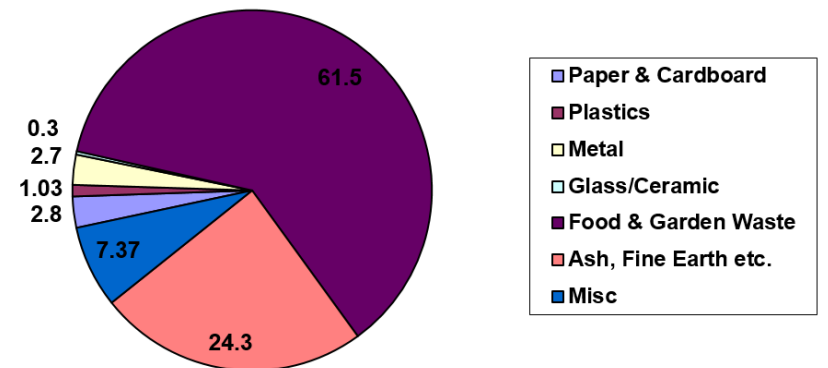

Fig 1: Percentage of Constituents of MSW in Panchkula

Volume and Density: The Volume and density was calculated by physically measuring the volume and weight of the uncompacted waste in the box type rickshaw (collection cart) of the collector. It was found to be $135 \mathrm{~kg} / \mathrm{m}^{3}$ which compares favorably with figures given in the seminal book "Environmental Engineering" by Howard S.Peavy, Donald R. Rowe and G. Tchobanologus, McGraw Hill, 1985 [6].

Evaluation of Methodology: After analysis of the waste generation trends, composition of the waste and the results of the public survey, the suitability of various prevailing practices was evaluated and it was evident from the evaluation that no single method in isolation is the best suited in itself. For example: a properly engineered landfill site will be necessary in any of the options adopted, as there will always be some waste at the end of the process to be confined to the land. Thus for the city of Panchkula, composting of the large quantity of organic waste generated, in combination with efficient recycling and landfilling was found to be the most suitable approach. Since there are different approaches available within this technical alternative of composting, the most suitable approach is carefully weighed and selected keeping all aspects in mind. Selection of best alternative has been done by using the Paired Comparison Technique tool [7].

\section{RESULTS AND DISCUSSION}

The actual examination of the system revealed that the physical management of MSW on ground is carried out by a mix of municipal officials, contractors' employees and private individuals. The figure 2 depicts the waste stream of the city of Panchkula. 


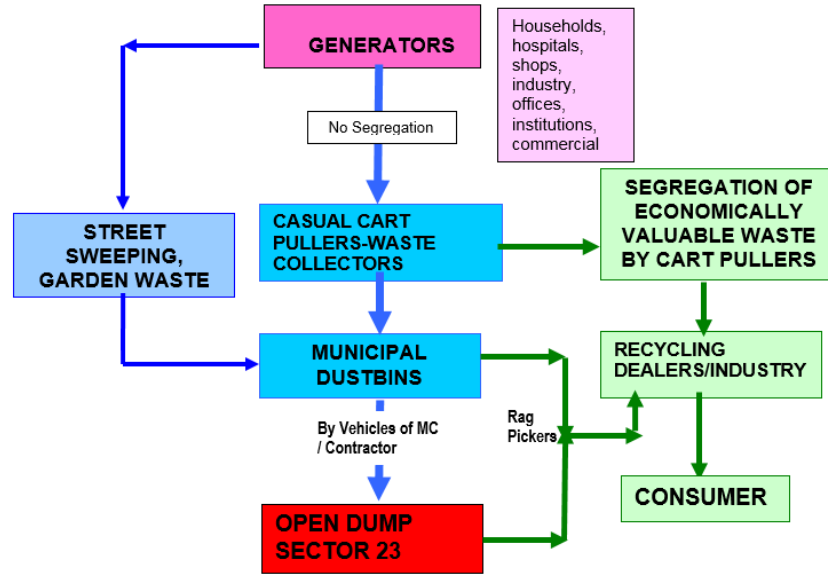

Fig-2 : Schematic of MSWM structure in Panchkula. (Source : First hand observation / study, visit to site by author and interaction with officials as well as Safai Karamcharis)

Assessment of the MSW Management Structure: The first link in the chain is the waste producer which is the resident or commercial establishment or an institution or medical facility etc. The waste is collected from the premises by rickshaw/cart pullers who are causal individuals employed by the Resident Welfare Association. These individuals segregate the economically valuable (recyclable) constituents of the generated waste and sell it in the informal market prevalent in the surrounding slum areas towards the North West of the city. Balance of the solid waste is dumped into dumper placers/open bins placed by the Municipal Corporation (MC). These bins are picked up by a contractor in vehicles of the $\mathrm{MC}$, put under his charge as part of the contract or driven/operated by MC employees themselves. The waste is transported and dumped at an open dumping ground in Sector 23 which is on the banks of Ghaggar River and in very close proximity of residential areas and important religious shrine of Gurudwara Nada Sahib. The citing of the dump site was done many years before residential sectors came up in the area. The solid waste of the complete town of Panchkula as well as surrounding areas dumped at this site. Some industries / private individuals, farmers and poultry owners directly dump their waste themselves in this location irrespective of its contents in complete contravention of all rules and regulations. The emphasis of the local authorities is to endeavor to ensure, clearing of the bins placed by them. Proper disposal / treatment is nowhere on the horizon. The assessment of the process is given below:-

(a) Staffing and Resources: The manpower, machinery and other resources employed by the Municipal Corporation are inadequate for proper management of the MSW of the city [8].

(b) Containers: Dumper Placers (DPs) of 3 Cubic m capacity are used for collection of solid waste centrally in sectors. However their lids are often missing/open and the capacity is insufficient to contain the days waste of some of the sectors. Resultantly, the collectors either throw away the waste on the ground or cart it all the way in their rickshaws/carts to Sector 23 dump. As a result the bins keep over flowing and attracting vectors like flies, animals and rag pickers posing a health risk besides poor aesthetics and odor. However, lately some improvement has been observed in this process.

(c) Awareness of Authorities and Public: The whole system of SWM is nonscientific and unprofessional. The priority of SWM is quite low on the political agenda, as can be seen from the infighting within the administrative set up of the city [9]. There is total lack of awareness and lack of will to implement the proper regulations on the part of the authorities which is evident from the indiscriminate dumping at Sector 23, open burning, scavenging, animal menace in the city etc. Somehow the public is also unaware. As long as waste is collected from their premises and the bin is not kept next to their house and is emptied regularly they are happy. In fact there is no provision for placing of large bins of the type under use presently. No spaces have been left for these in the town planning and they lie around haphazardly on pavements, empty plots, road sides and parking lots with no platform or enclosures, attracting animals, flies and rag pickers, who in turn create litter and untidy mess around these bins. The aim of Municipal Corporation is to clear these bins to a maximum possible extent. There are no public education / awareness schemes. No one is fined for littering.

(d) Segregation of Waste Streams: There is no segregation at any level except by the waste collectors who remove anything of economic value which is mostly paper, cardboard, plastic and sometimes rubber, glass metal etc. However, lately some plans are afoot to implement segregation at source in some of the wards. How will the waste generator respond remains to be seen as there is no/very weak public awareness/education campaign or effort.

(e) Landfill: The open dump where the MSW of the city is being dumped does not meet any laid down criteria. It is a low lying ravined area located on the bank of River Ghaggar and is astride its tributary nallahs. It is located in the middle of proposed and already partially developed residential sector. There is no weigh bridge, no liner, no leachate collection system and no monitoring. The site presents an unaesthetic picture of squalor and neglect. Rag pickers, animals and various other insects and vectors can be found in abundance. The site is not notified by the State Pollution Control Board as approved landfill site. The site does not meet the National Green Tribunal norms [8]. Since past few months some machinery and workers can be seen putting in inadequate effort of compacting the already dumped waste and spreading soil over it.

(f) Absence Of Any Treatment/Processing Facility: There is no facility for treatment / processing of MSW. A state of the art Integrated Solid waste Management Project (ISWMP) proposed to be set up by a private company on the 33 acres site near the present dump site is being opposed by the residents and its future remains unclear. Under public pressure and due to pressure from State Pollution Control Board, an alternate site was earmarked but this too met with objections and litigations as it is closer to

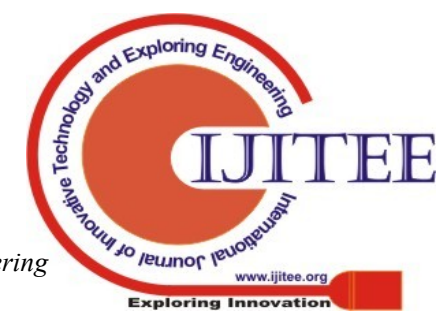




\section{Optimal Municipal Solid Waste Management of A City in North India}

residential areas as compared to the present open dump [10]. Meanwhile, simultaneously, in order to reduce the quantity of waste, some initiatives at a small scale are being taken by the MC in terms of segregation of bio degradable waste and composting the same in a small composting facility created in sector 12. Training is also being given for small scale back-yard composting to staff of commercial establishments like hotels and restaurants. An initiative by the RWA and some NGOs to segregate waste at the source i.e. by the residents failed to take off due to lack of adequate awareness and motivation to participate by the residents and waste collectors[11].

Evaluation of Suitable Disposal Methods: Every city has its own set of peculiar conditions and compulsions as regards suitability of a SWM system. A system suitable for one city may not be suitable for another in the close vicinity. However the basic aspects which can't be ignored in any MSW management are : Financial and Environmental Sustainability, Social Acceptability, Participation of Residents and Technical Feasibility. After analysis of the waste generation trends and composition of the waste, the suitability of various prevailing practices is evaluated.

(a) Open Dumping: This is being currently practiced in Panchkula and most of the cities of the country. It is environmentally one of the most unsound practices and undesirable from the health and sanitation point of view. As brought out earlier, this practice will have to be discontinued at the earliest.

(b) Landfilling: A properly engineered landfill system is a suitable method for disposal. However it needs proper management and operation. Pollution potential of a landfill continues to be high if putrescible matter is disposed in it. The leachate infiltration into ground water and surface water bodies also poses a risk. The areas in the vicinity of Panchkula are crisscrossed with nallahs and rivulets and the water table is fairly high. Also, the complete drinking water supply of the city of both Panchkula and Chandigarh is based on ground water. The landfill therefore will have to be well designed and managed.

(c) Composting: This is one of the best options as the percentage of compostable waste in the city is quite high. The climate of the area is also suitable for the process. As the majority of people are willing to participate in the segregation at source process, this is a suitable option. There is adequate market available for compost in the nearby areas of the city.

(d) Recycling: Only some of the contents of the waste are recyclable. These have considerable economic value which can be ploughed back into the process. As the time passes, humanity is finding ways and means to recycle more and more waste constituents earlier considered useless. Any system adopted has to therefore give adequate importance to this process.

Incineration: This process is used to reduce the volume of waste with or without energy generation. As the organic component and the inert component is high, the MSW of the city is not likely to have an adequate calorific value to make any energy recovery process economically viable. Similar projects elsewhere have run into problems. Moreover the amount of waste generated will not reach the levels where the setting up of a large WTE plant becomes a financially sound prospect. On the other hand, pure incineration to reduce the volume of waste is a wasteful and environmentally unsound practice. Incineration as an option is therefore ruled out.

Available Options: It is evident from the above discussion that no single method in isolation is the best suited in itself. For example: a properly engineered landfill site will be necessary in any of the options adopted, as there will always be some waste at the end of the process to be confined to the land. Thus for the city of Panchkula, composting of the large quantity of organic waste generated, in combination with efficient recycling and landfilling, is the most suitable approach. In addition, suitable segregation, collection and transportation processes will also have to be designed in order to implement this option. For the evaluation of the technical alternatives, the techniques of "Trade off Analysis" and "Paired Comparison (Ranked and Unranked)" can be used. The "Paired Comparison Technique" has been made use of in this study in order to arrive at suitable alternatives for the study area. Within the technical alternative of composting, there are three different approaches available. These are explained below. The most suitable approach will have to be carefully weighed and selected keeping all aspects in mind.

(a) Backyard or Household Composting (T1): As the MSW comprises mainly of residential waste with a very high organic component, this can be handled at source itself resulting in reduced load on the collection, transportation and disposal site. This is carried out easily by temporarily storing the waste in a plastic bin which is periodically emptied in a larger vermicomposting or composting unit placed in the backyard or outside. Recyclables and garbage will be collected as usual with the existing system. However in case of low percentage of participation the disposal of the compostable waste will have to be done in the landfill, which is not a preferred option. Public will have to be educated about the process in detail and houses with backyard space only can implement this.

(b) Centralized Composting of Source Segregated Waste (T2): In this method waste is segregated at the source itself in which a resident separates the waste into biodegradable and non-biodegradable waste in two separate bins. A third bin could also be provided for the recyclables. The collection vehicle collects these in three different compartments provided in the vehicle. The waste is delivered to a sorting, transfer and dispatch station. From here the organic waste is transported to the central composting farm. The recyclables are sold and balance waste is sent to the landfill. As per the results of the survey the public is likely to actively participate in the program provided they are kept adequately educated and motivated. Continuing community awareness programs are an inseparable part of this system. The collection vehicles will have to be modified with three compartments instead of one. If successfully implemented, this is the ideal system. 
(c) Centralized Composting of Mixed Waste (T3) : In this the collection vehicle will collect all the waste as mixed waste and transport it to a processing cum transfer facility where the organic, recyclable and land fillable waste is separated out manually / mechanically. Public involvement in this is limited to placing the waste in a bin. The process of segregation of waste into compostable and non-compostable will be difficult and resource intensive process.

Selection of Best Alternative by Paired Comparison Technique: To evaluate any alternative weighing-scaling or ranking checklists can be used. "Scaling" refers to assignment of algebraic scales or letter scales to the impact of each alternative being evaluated on each identified environmental factor. "Ranking" checklists are where alternatives are ranked from best to worst in terms of their potential impacts on the identified environmental factors. A set of criteria or environmental/decision factors have been selected which will be used to evaluate the technical alternatives considered above [7]. These factors are:-
(a) Achievement of Objective. (C1)
(b) Public Participation. (C2)
(c) Economy. (C3)
(d) Adaptability/Flexibility. (C4)
(e) Simplicity/Functionality. (C5)
(f) Future Scope and Carrying Capacity. (C6)

Importance Weight Assignment to Factors : In order to give an importance weight assignment we carry out a paired comparison amongst these criteria to decide their comparative importance. This is given in table 2 below:-

Table- 2: Paired Comparison for Importance Weight Assignment to Factors

\begin{tabular}{|l|l|l|l|l|l|l|l|l|}
\hline & C1 & C2 & C3 & C4 & C5 & C6 & SUM & FIC \\
\hline C1 & 0 & 0 & 1 & 1 & 1 & 1 & 4 & 0.267 \\
\hline C2 & 1 & 0 & 1 & 1 & 1 & 1 & 5 & 0.333 \\
\hline C3 & 0 & 0 & 0 & 1 & 1 & 1 & 3 & 0.200 \\
\hline C4 & 0 & 0 & 0 & 0 & 0 & 1 & 1 & 0.067 \\
\hline C5 & 0 & 0 & 0 & 1 & 0 & 1 & 2 & 0.133 \\
\hline C6 & 0 & 0 & 0 & 0 & 0 & 0 & 0 & 0.00 \\
\hline $\begin{array}{l}\text { TOTA } \\
\text { L }\end{array}$ & & & & & & & 15 & 1.00 \\
\hline
\end{tabular}

FIC (Factor Importance Coefficient) = the sum value for an individual factor/sum for all the factors.

The total of the sum column should be equal to $n(n-1) / 2$ where $n$ is the no. of factors. Here $n=6$. Therefore $6(6-1) / 2=15$ hence true. From this comparison technique it is concluded that $\mathrm{C} 2$ i.e. public participation is the most important factor followed by $\mathrm{C} 1, \mathrm{C} 3, \mathrm{C} 5, \mathrm{C} 4$ and $\mathrm{C} 6$.

Ranking of Alternatives: The alternatives are evaluated by comparing each alternative to other alternative relative to each of the six factors separately.

(a) Ranking of Alternatives relative to $\mathrm{C} 1$ (Achievement of Objective/ Identified Need):-

Table- 3 : Ranking of Alternatives Relative to C1

\begin{tabular}{|l|l|l|l|l|l|}
\hline & T1 & T2 & T3 & SUM & ACC \\
\hline T1 & 0 & 0 & 0 & 0 & 0 \\
\hline T2 & 1 & 0 & 1 & 2 & 0.67 \\
\hline T3 & 1 & 0 & 0 & 1 & 0.33 \\
\hline $\begin{array}{l}\text { TOTA } \\
\text { L }\end{array}$ & & & & 3 & 1.00 \\
\hline
\end{tabular}

$\mathrm{ACC}=$ Alternative Choice Coefficient. It has been seen in the above calculation that relative to the factor $\mathrm{C} 1$ i.e. Achievement of Objective/ Identified Need, T2 is the best alternative followed by $\mathrm{T} 3$ and $\mathrm{T} 1 . \mathrm{T} 2>\mathrm{T} 3>\mathrm{T} 1$.

(b) Ranking of Alternatives relative to C2 (Public Participation):-

Table- 4: Ranking of Alternatives Relative to C2

\begin{tabular}{|l|l|l|l|l|l|}
\hline & T1 & T2 & T3 & SUM & ACC \\
\hline T1 & 0 & 0 & 0 & 0 & 0 \\
\hline T2 & 1 & 0 & 0 & 1 & 0.33 \\
\hline T3 & 1 & 1 & 0 & 2 & 0.67 \\
\hline $\begin{array}{l}\text { TOTA } \\
\text { L }\end{array}$ & & & & 3 & 1.00 \\
\hline
\end{tabular}

It has been seen in the above calculation that relative to the factor C2 i.e. Public Participation, T3 is the best alternative followed by $\mathrm{T} 2$ and $\mathrm{T} 1$.

(c) Ranking of Alternatives relative to C3 (Economy):-

Table- 5: Ranking of Alternatives Relative to C3

\begin{tabular}{|l|l|l|l|l|l|}
\hline & T1 & T2 & T3 & SUM & ACC \\
\hline T1 & 0 & 1 & 1 & 2 & 0.67 \\
\hline T2 & 0 & 0 & 1 & 1 & 0.33 \\
\hline & & & & & \\
T3 & 0 & 0 & 0 & 0 & 0.00 \\
\hline
\end{tabular}




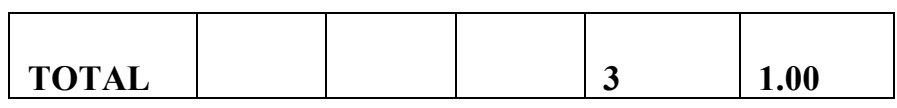

It has been seen in the above calculation that relative to the factor $\mathrm{C} 3$ i.e. Economy, $\mathrm{T} 1$ is the best alternative followed by $\mathrm{T} 2$ and $\mathrm{T} 3 . \mathrm{T} 1>\mathrm{T} 2>\mathrm{T} 3$.

(d) Ranking of Alternatives relative to C4 (Adaptability/Flexibility):-

Table- 6: Ranking of Alternatives Relative to C4

\begin{tabular}{|l|l|l|l|l|l|}
\hline & T1 & T2 & T3 & SUM & ACC \\
\hline T1 & 0 & 1 & 1 & 2 & 0.67 \\
\hline T2 & 0 & 0 & 1 & 1 & 0.33 \\
\hline T3 & 0 & 0 & 0 & 0 & 0.00 \\
\hline $\begin{array}{l}\text { TOTA } \\
\text { L }\end{array}$ & & & & 3 & 1.00 \\
\hline
\end{tabular}

It has been seen in the above calculation that relative to the factor C4 i.e. Adaptability/Flexibility, T1 is the best alternative followed by $\mathrm{T} 2$ and $\mathrm{T} 3 . \mathrm{T} 1>\mathrm{T} 2>\mathrm{T} 3$.

(e) Ranking of Alternatives relative to $\mathrm{C} 4$ (Simplicity/Functionality):-

Table- 7: Ranking of Alternatives Relative to C5

\begin{tabular}{|l|l|l|l|l|l|}
\hline & T1 & T2 & T3 & SUM & ACC \\
\hline T1 & 0 & 1 & 1 & 2 & 0.67 \\
\hline T2 & 0 & 0 & 1 & 1 & 0.33 \\
\hline T3 & 0 & 0 & 0 & 0 & 0.00 \\
\hline $\begin{array}{l}\text { TOTA } \\
\text { L }\end{array}$ & & & & 3 & 1.00 \\
\hline
\end{tabular}

It has been seen in the above calculation that relative to the factor C5 i.e. Simplicity/Functionality, T1 is the best alternative followed by $\mathrm{T} 2$ and $\mathrm{T} 3 . \mathrm{T} 1>\mathrm{T} 2>\mathrm{T} 3$.

(f) Ranking of Alternatives relative to C6 (Future Scope and Carrying Capacity):-

Table- 8: Ranking of Alternatives Relative to C6

\begin{tabular}{|l|l|l|l|l|l|}
\hline & T1 & T2 & T3 & SUM & ACC \\
\hline T1 & 0 & 0 & 0 & 0 & 0 \\
\hline T2 & 1 & 0 & 1 & 2 & 0.67 \\
\hline & & & & & \\
T3 & 1 & 0 & 0 & 1 & 0.33 \\
\hline
\end{tabular}

It has been seen in the above calculation that relative to the factor C6 i.e. Future Scope and Carrying Capacity, T2 is the best alternative followed by $\mathrm{T} 3$ and $\mathrm{T} 1 . \mathrm{T} 2>\mathrm{T} 3>\mathrm{T} 1$.

\section{Development of the Decision Matrix and Product Decision Matrix:}

Table- 9: FIC and ACC Values for Decision Matrix

\begin{tabular}{|l|l|l|l|l|}
\hline \multirow{2}{*}{ Factors } & FIC & \multicolumn{3}{|c|}{ ACC Values by Alternatives } \\
\hline & & T1 & T2 & T3 \\
\hline & & & & \\
C1 & 0.267 & 0 & 0.67 & 0.33 \\
\hline C2 & 0.333 & 0 & 0.33 & 0.67 \\
\hline C3 & 0.200 & 0.67 & 0.33 & 0 \\
\hline & & & & \\
C4 & 0.067 & 0.67 & 0.33 & 0 \\
\hline C5 & 0.133 & 0.67 & 0.33 & 0 \\
\hline C6 & 0.000 & 0 & 0.67 & 0.33 \\
\hline
\end{tabular}

Table- 10: Product Matrix for Decision Making

\begin{tabular}{|l|l|l|l|}
\hline & T1 & T2 & T3 \\
\hline C1 & 0 & 0.179 & 0.088 \\
\hline C2 & 0 & 0.110 & 0.223 \\
\hline C3 & 0.134 & 0.066 & 0 \\
\hline C4 & 0.045 & 0.022 & 0 \\
\hline C5 & 0.089 & 0.044 & 0 \\
\hline C6 & 0 & 0 & 0 \\
\hline Total & 0.268 & 0.421 & 0.311 \\
\hline
\end{tabular}

Deductions: The total of the product for each alternative indicates that $\mathrm{T} 2$ would be the best choice i.e. centralized composting of source segregated organic waste. This is followed by T3 i.e. centralized composting of mixed waste and last choice is T1 i.e. Backyard/Household composting. This shows that the public is willing to participate but only to a limit. Probably backyard composting is considered to be a cumbersome process and people are also discouraged due to lack of space. Lack of knowledge may also be a contributory factor. However , even if T2 alternative is implemented, T1 should still 
be encouraged as it will reduce the waste stream.

\section{Proposed Municipal Solid Waste Management System for Panchkula}

After the detailed analysis of the existing SWM system in the city of Panchkula, a suitable futuristic SWM system for the city is proposed. The new system is environment friendly, low investment, self-sustaining and an integrated SWM system. It is highly adaptable and suitable for implementing future concepts like Zero Waste generation. The system is designed to cater for a time span of 20 years. It can however sustain longer, as all elements are designed on modular principle. The scope of this study does not envisage a detailed design of the project involving the detailed design of the processing plant, composting plant and the engineered landfill. The design has therefore only been conceptually and broadly given out. The detailed project design is subject for a future separate Detailed Project Report (DPR) and is therefore not included as part of this study. Incineration and WTE has not been considered as an option for Panchkula due to low calorific value of the MSW and pollution potential of such plants. No organic matter in the proposed system is planned to be disposed in the landfill thus reducing its pollution and greenhouse gas effect potential -

considerably. The capacity which the proposed system will have to cater for is calculated in the next paras.

(a) Population of Panchkula: As per the Census of India 2011, the population of Panchkula city was 2,11,355 in the year 2011[3]. The decadal growth rate of population in last two decades (1991 to 2001 and 2001 to 2011) in Haryana is $28.06 \%$ and $19.90 \%$. The decadal growth rate in Panchkula has been $51.16 \%$ and $19.32 \%$ for these decades [2]. As is the national trend, this rapid growth rate is bound to decrease to an approximate average of $15 \%$ in the following decades (2011-2021, 2021-2031 and 2031-2041) as the city has limited scope to expand. The population of Panchkula is therefore projected to be approximately 3,20,850 by 2041 .

b) Solid Waste Generation: Presently the city of Panchkula produces approximately 86 MT of MSW. Due to rapid development and improved standards of living, the consumption pattern undergoes a change. Increased quantities of plastics, paper etc. will be used. The MSW generation rate increase is estimated to be a conservative $1.33 \%$ per year per capita [12]. However, there are other studies which suggest that the increase in the rate of MSW generation is likely to be much more than this and is likely to rise steeply due to rapid GDP growth rate and peak at levels of MSW generation rates of developed economies [13]. Hence for design purposes, the solid waste generation rate in 2041 is assumed to be $0.750 \mathrm{~kg} / \mathrm{p} / \mathrm{d}$. Therefore the waste generated per day by the city in 2041 would be 240 MT.

Salient Aspects of Proposed System: The salient aspects of the proposed system are enumerated below:-

(a) Integrated SWM System: - The proposed system is an integrated solid waste management system addressing all stages of the chain simultaneously. There are actions which are beyond the control of the local authorities and can be implemented by the state/ central Govt. only.

(b) Takes Care of Economic \& Social Aspects: - The Urban poor who are making their living from the MSW of the city presently, have been taken into consideration and will be absorbed to the maximum extent. As far as financial burden on the residents is concerned, it will only be marginally higher.

(c) A completely sealed system: - In the proposed system, waste is considered to be a resource and therefore there is no scope for scavenging/ removal of recyclable material except by the designated process. Thus there is no loss of resource.

(d) Public Involvement: - Public involvement and interest is very crucial for the success of the system.

(e) No adverse environment and health impact.

(f) Designed to facilitate implementation of Zero Waste system ultimately.

(g) Product Design: In order to ensure that the waste stream steadily reduces and finally in the end we discard minimal or negligible quantities in the future, suitable changes in design of product / consumer items will be required. These will have to ensure that the product ends up as Zero Waste i.e. practically disappears or is used up in another process with no residue / left over. This is however a very difficult target to achieve. It is also beyond the control of the local authorities and requires initiative by the Government. Laws requiring the producers to start producing differently will have to be urgently and strictly implemented. Economic incentives are the best way to achieve compliance. Awareness of the Public in order to encourage them to use only green, no waste/residue type of products is vital. This is a key thrust area of the proposed system requiring community education and sustained effort.

Mechanics of Proposed system: The system envisages the participation of a highly aware and motivated public, who would segregate the wet (compostable), dry (recyclable) and domestic hazardous waste at source itself. The waste would be collected from every household / premise once a day by an automotive vehicle having separate compartments which would transport it to a facility called the Sorting, Transfer and Dispatch Station. This facility is a type of transfer station with additional facility of inspecting and sorting the waste. It has three streams i.e. compostable waste, recyclable waste and other miscellaneous inert/inorganic waste streams. The bio-medical and hazardous waste is proposed to be handled in separate facilities and is not to be mixed with this MSW stream. From the sorting and transfer station the waste will be disposed of by either of the following methods. Compostable waste will be dispatched to the composting farm. Recyclables will be segregated and stored temporarily in the facility at storage created especially for this purpose, from where they will be lifted by the recycling dealers/ contractors in their transport periodically on as

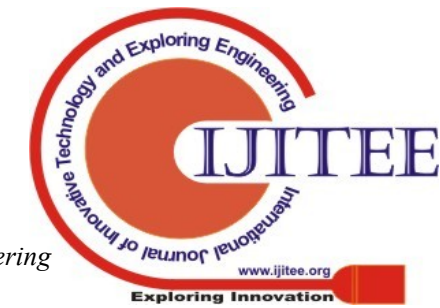




\section{Optimal Municipal Solid Waste Management of A City in North India}

is where is basis. Any hazardous waste would be sent to the appropriate hazardous waste disposal facility/ handling agency. Balance of the inorganic/ inert waste will be landfilled. It is expected that as the time passes, this stream would continuously reduce.

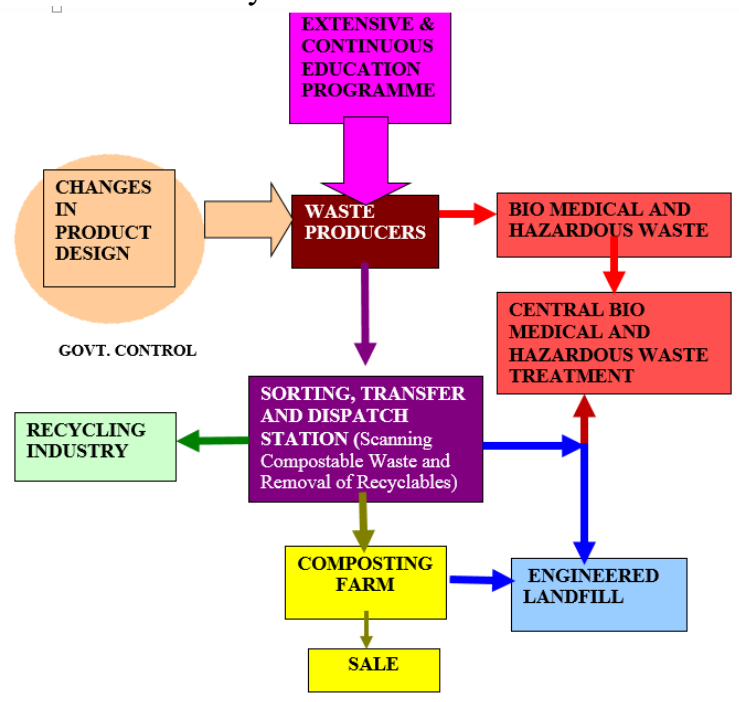

Fig. 3 Proposed Scheme for Panchkula

Description of Elements of the Proposed System: Each of the elements of the proposed system is briefly discussed below:-

(a) Waste Producers: They are the most vital link in the system and their co-operation, participation, education and motivation is of the highest importance. Well-designed community education programs through leaflets, advertisements, commercials, door-door visits and demos to house wives school programs etc. will have to be started well before the system is put into place. These programs have to be continuous and ongoing with frequency and intensity being the maximum during the initial period. The residents will segregate the waste into three parts, put it in biodegradable bags and store them in three bins of different colors meant for wet, dry and household hazardous waste. These would be placed inside the premise / home (ground floor) and the specially designed collection vehicles will pick up the waste from every location. Strict enforcement of rules and imposition of fines will have to be done. The collection vehicle driver reports the violation/ littering to the inspector who would visit the violator and impose penalty. Unsegregated waste will not be picked up. With improvement in product design and implementation of the above measures the quantity of waste which has no use (i.e. it cannot be recycled/ composted) will steadily come down over a period of time and waste stream going to landfill should considerably reduce.

(b) Collection: The city of Panchkula is so designed that it is ideally suited for collection of waste from houses by small collection vehicles. Collection by vehicles will be more economical in terms of time, fuel, manpower and efficiency. Each vehicle has a capacity of $675 \mathrm{Kgs}$ and has three compartments with individual mechanical articulation, to enable dumping sideways. These are required so that each compartment can be emptied in the sorting and transfer station in the compostable, recyclable or hazardous waste sorting stream. Such a vehicle can be easily manufactured based on the choices of Maruti Omni Pick Up Van or Tata Ace Truck which would be CNG based. A battery operated version could also be designed for the purpose. Three to four such vehicles would be required for each residential sector. Each vehicle will be served by a driver and a crew of one person who will be the collector. Each vehicle will collect garbage from door to door from approximately 230 houses in an 8 hours cycle.

(c) Sorting, Transfer and Dispatch Station: It is proposed to establish two such facilities for the city. In effect the complete MSW generated in the city will be transported to these two centers by collection vehicles. Here, the already segregated waste will be fed into three streams, namely, compostable, recyclable and household hazardous waste streams. Waste in each stream will be sorted mechanically as well as inspected manually and any undesirable matter will be removed and re-routed to the appropriate stream. The waste will then be transferred to larger vehicles and dispatched for disposal. These facilities are simple, low budget, non-sophisticated units with the function of Sorting, Segregation and Material Recovery by manual as well as mechanical means, dispatching of waste to disposal site and disposal of segregated recyclables.

(d) Capacity of Sorting, Transfer and Dispatch Station: As per calculation above the population of Panchkula city is likely to go up to $3,20,850$ by the year 2041 and the generation rates are likely to be $0.750 \mathrm{~kg} / \mathrm{p} / \mathrm{d}$. Accordingly the total waste generated in the city at that point of time will be $240 \mathrm{MT} / \mathrm{d}$ (metric tons per day). It is therefore proposed to establish two sorting and transfer stations, each with a capacity to handle $125 \mathrm{MT} / \mathrm{d}$. Initially each plant will have capacity of $50 \mathrm{MT} / \mathrm{d}$. Thereafter this will be enhanced by adding additional units consisting of hopper, conveyor and delivery chute. Space for this enhancement will be catered for besides the existing facilities. Alternately only one plant of capacity $125 \mathrm{MT} / \mathrm{d}$ can be established. The second plant can be established after period of 10 years. In case it is felt that due to implementation of new laws and legislations the quantity of waste being generated is steadily reducing, the additional units could be of lower capacity the design of which can be easily modified. The plants will be located at the two opposite ends of the city where land is presently available (including the present open dump site which will have to be re-engineered). The maximum turn around distance for the farthest sector is within $10 \mathrm{kms}$.

Recycling: The recyclable waste stream has the maximum number of persons deployed for inspection, as the waste will not only be inspected for undesirable material but will also be segregated into paper, plastic, metal glass, wood and cans. The segregated waste will be put into wheel barrows and dumped into the storage shed located close by. The recyclables will then be auctioned off. The contractor / dealer will remove the material from the premises in his own transport periodically.

(f) Composting: The already segregated compostable material is received at the 
sorting and transfer station where it is shredded to smaller size and thoroughly inspected to efficiently remove inorganic / undesirable material. This is an important step, as many a composting schemes have failed due to large percentage of these materials in the organic stream. This stream will consist of all the food and garden waste which comprises approximately $61.5 \%$ of MSW generated. This stream will be kept separated by some distance from the other two within the same plant due to hygiene reasons. As regards transportation, it is more economical to transfer the compostable waste into larger capacity vehicles to transport it over larger distance to the compost farm rather than transport it in small quantities by directly sending all the collection vans to the compost farm located $20 \mathrm{kms}$ away. At present only 48MT of compostable waste is being produced. However at the end of the design period this is likely to go up to 148 MT per day. The composting farm will therefore be expanded in stages. Presently it will have to be developed to cater for 60 MT of compostable waste every day.

(g) Landfill: At present the site being used as open dumping ground should be closed forthwith and a proper engineered landfill with cover, liner and leachate collection system will have to be created. An elaborate gas recovery system for energy recovery is not desirable as it is not proposed to dump any organic waste in the landfill. Gases in a landfill are primarily produced due to the aerobic and anaerobic decomposition of organic solid material. Moreover the gas recovery system may not be economically viable for the size of the landfill envisaged. However production of gas cannot be totally ruled out as there are various biological, physical and chemical events that occur in a landfill. Therefore, as the quantity of MSW increases in the landfill, provision will have to be made for proper venting of gases to the atmosphere.

\section{CONCLUSION}

Waste problems exist wherever there is a human population. The characteristics of these problems vary from one place to another, and with time, as societies develop. Although they may first appear to be local issues, the scope and magnitude of these problems are increasing as population density and standards of living rise. The time is past when waste management could be considered in isolation. Environmental, technological and economic factors all have some bearing, and the need to conserve resources also demands attention. The present system of MSW management in Panchkula is unscientific, and inefficient and a potential environment and health hazard. The issue needs to be urgently addressed and there is a requirement to upgrade the existing system immediately. Public participation and a decentralized SWM system is a suitable solution for the city wherein education of the waste generators, inclusion/rehabilitation of the persons presently involved in the waste collection/recycling activities and a scientific cum social approach will be the keys to its success.

\section{REFERENCES}

1. Population Census of India https://census2011.co.in/
2. Bhalla Anuj, Dr, 2014 , "Decadal Population Growth Rate of Haryana: A Spatial Temporal Analysis", Geography-An International Journal-125,Vol-XIII(6), Aug 2017, PP 74-75.

3. Official Website of Panchkula http://panchkula.nic.in on 24 May 2019.

4. Kaushal Yuvraj,2018, "Spotlight: The Smoky Mountain of Panchkula", Hindustan Times, Panchkula, 28 Jun 2018.

5. CPCB website www.cpcb.nic.in/

6. Peavy Howard S., Rowe Donald R., Tchobanologous G.,(1985), "Environmental Engineering", McGraw Hill, NY.

7. Baetz B. W and Korol R. M. (1995), "Evaluating Technical Alternatives on Basis of Sustainability”, J. of Professional Issues in Engg. Education and Practice. Vol.121, no.2, p. 102.

8. Gupta Vivek 2017, "Panchkula Pangs: No Work All Fight", HT, Panchkula, 01 May 2017 and "City Laid to Waste: Great Mess Called Panchkula Garbage”, HT, Panchkula,04 May 2017.

9. Thakur Bhartesh Singh, 2017, "How MC Panchkula Failed its People", HT 23 April 2017.

10. Dutta Saptarishi, 2017, "Panchkula Garbage Problems Mount Despite a Proposed New Landfill”, HT, 06b Oct 2017.

11. The Times Of India, Panchkula, 11 Mar 2019, "Waste Segregation Training for Panchkula Residents".

12. Singhal S and Pandey S (2001) "Solid waste management in India - Status and future directions", TERI Information monitor on Environmental Science, Vol.6, No.1, pp 1-4.

13. Goel Sudha, 2008, "Municipal Solid Waste Management in India - A Critical review". Journal of Environment Science and Engineering.50.319-328.

14. Parashar Neeraj, 2007, “A Comprehensive and Critical Study of Solid Waste Management System of A Modern And Planned City of North India", A thesis submitted to PEC Chandigarh, in partial fulfillment of the requirements for the award of the degree of Master of Engineering in Environmental Engineering

\section{AUTHORS PROFILE}

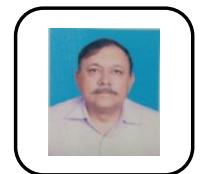

BRIGADIER NEERAJ PARASHAR, Veteran, served in the Corps of Engineers, Indian Army, in various technical and other appointments in a career spanning over 35 years. He received his B. Tech degree from College of Military Engineering (JNU), Pune, an MSc degree in Defense and Strategic Studies from Madras University in 1996 and M. Tech from PEC University, Chandigarh in 2007. He is a $\mathrm{PhD}$ research scholar at RIMT University, Punjab, India. He has vast engineering experience in the field including as Chief Engineer of large infra projects. His research interests include environmental engineering, waste management and renewable energy.

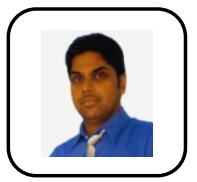

Dr. SANDEEP SINGLA received his B Tech degree in Civil Engineering in 2001 from Punjab Technical University, Jalandhar, M. Tech from Thapar Institute of Engineering and Technology, Patiala in 2004 and $\mathrm{PhD}$ degree from National Institute of Technology, Kurukshetra in 2018. Presently, he is working as Professor and Head of Department of Civil Engineering, RIMT University, Punjab, India. He has published more than 60 papers in national and international journals/conferences. He has guided more than $30 \mathrm{M}$. Tech thesis

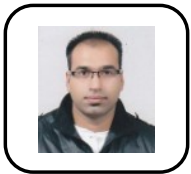

Punjab, India.
ANUJ SACHAR received his B Tech degree in Civil Engineering in 2005 from Punjab Technical University, Jalandhar, M. Tech from RIMT University, Punjab. Presently, he is working as Assistant Professor in Department of Civil Engineering, RIMT University,

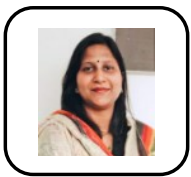

ANJALI GUPTA did her B. Tech degree in Civil Engineering in 2001 from GZSCET, Bathinda and M. Tech from National Institute of Technology, Kurukshetra in 2003. She is a PhD research scholar in the Department of Civil Engineering at National Institute of Technology, Kurukshetra. She is presently working as an Associate Professor at Department of Civil Engineering, Manav Rachna Institute of Research and Studies, Faridabad. She has 14 years of academic and industrial experience and has published 08 research papers in various reputed journals. Her research interests include geo-environment, waste management, Fuzzy and Artificial Intelligence.

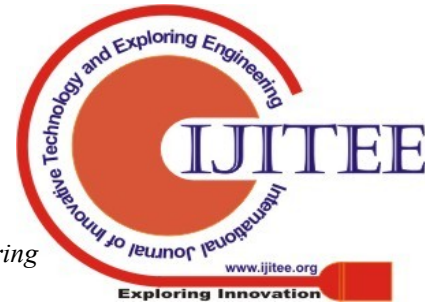

